\title{
Professional desire, competence and engagement in IS context
}

\author{
Peter M Bednar ${ }^{1}$ and Christine Welch ${ }^{2}$
}

\begin{abstract}
This paper attempts to address the failings of a predominant paradigm in IS research and practice that emphasises technological determinism. This paradigm makes use of a false belief in the power of rationality in organizational decision-making, and a mythology in which organizational actors can be viewed as passive 'users' of technology. We wish to create a discussion of the nature and role of professionalism as an expression of more than technical competence. Both system analysts and organizational stakeholders (e.g. 'users') are to be viewed as professionals. We discuss desire, exercise of will and their role in professional judgment in relation to transcendent values espoused within communities of practice. We go on to relate this to the environments of Information Systems research and practice. It is pointed out that many researchers, over a number of years, have dealt with these issues in relation to effective management of technological development and organizational change. The paper attempts to encourage renewed attention to interpretivist perspectives on IS development and organizational change, including recognition of the importance of contextual dependencies.
\end{abstract}

\section{Professional Desire and Will}

This paper is concerned with the nature of professional competence - how it is acquired, how it is demonstrated and how it is maintained. These issues are explored and discussed with particular reference to the field of Information Systems. We problematise a prevailing paradigm of technological determinism, involving a false belief in the power of rationality in organizational decision-making [1-12], and a mythology in which organizational actors can be viewed as receiving passive 'users' of technology [13-16]. We argue that professionalism is demonstrated through a combination of factors. While these will include possession of appropriate, job-relevant skills and knowledge these are insufficient in themselves without

\footnotetext{
${ }^{1}$ School of Computing, University of Portsmouth, Portsmouth, UK; email: peter.bednar@port.ac.uk

${ }^{2}$ Department of Strategy \& Business Systems, University of Portsmouth, Portsmouth, UK; email: christine.welch@port.ac.uk
} 
a desire to engage. A professional is someone who is able to reflect upon practice of certain skills in context, and to relate these reflections to a body of standards and values that transcend the immediate job role in which she finds herself at a given time. Often, this involves membership of a wider community of practice formal or informal. For instance, an accountant may become qualified through an examination system provided by a professional association (e.g. an Institute of Chartered Accountants). Having passed the examinations, she has demonstrated technical competence but membership of the Institute (conferring the designation 'Chartered Accountant') requires further evidence of probity and ability to learn through reflection, demonstrated through work experience and sponsorship by existing members. This status can be lost if the person is later found to lapse in ethical standards or conduct. If, for instance, the accountant's current employer were to ask her to 'cook the books', her loyalty to her community of practice should prevail so that she would give up the job rather than her pride in her professional standards. It is clear that a number of dimensions contribute to the professional conduct of the person described above. First, acquisition of technical skills and knowledge enable her to act in her formal role, e.g. to prepare a balance sheet or appraise alternative investments. However, why would she act in a particular way? How would she improve her professional practice over time? What would govern whether she complies with any particular instruction to act in a certain way? We suggest that professional competence implies not only skill/knowledge in a particular field, but desire to apply that knowledge in accordance with certain values, and engagement with the context of application such that reflection can lead to a productive learning spiral [12-18]. It might be expected then that a professional would engage in extra role behaviour, such as suggesting innovative methods $[7,8,19,20]$. It is through attachment to a transcendent system of values and standards that we recognise a professional at work, as opposed to a capable amateur or a charlatan. This attachment constitutes what we tend to refer to as professional pride.

These matters have long been recognised in the fields of organizational behaviour and human resource management through the phenomena of formal and informal organizations [1-3,9-11,21-25]. Within the formal structure, a person may have a job description expressed in terms of appropriate skills, knowledge and roles. However, the everyday experience of a professional is likely to bear only a loose resemblance to this description, as the actual role carried out is created and re-created in conjunction with colleagues and taking into account professional standards. The desire to demonstrate skills in context according to particular standards and values is demonstrated in part through the informal organization. Sometimes, when faced with a dilemma, a person will justify an action by the words 'I had no choice!' e.g. this is an excuse that has sometimes been put forward by concentration camp guards who claim they have took actions normally deemed unacceptable because their own families were threatened otherwise. The suggestion that there is no choice here is a fallacy $[2,3,26]$. What the person is actually saying is that, weighing up the potentially unpleasant consequences of each available choice, they took the line of least resistance. Of course, we cannot as- 
sume such choices always result from (conscious rational reflection of) resignation of responsibility, e.g. if a judge who disapproves of the death penalty nevertheless imposes it on a convicted person, he might say 'I have no choice; that is the penalty laid down by law'. This could be an abrogation of his responsibility as a human being to follow his conscience. On the other hand, he might be thinking that the alternative (to resign) would result in more prisoners being condemned in the future (by his replacement) in circumstances where the sentence was not mandatory. Professionalism requires that we recognise the choices we make, their relationship to a wider value system, and their impact upon the contexts of professional life.

Turning specifically to an IS context, we can observe that system failures often have their origins in ignoring emotional engagement, informal communication, personal investment by professionals in the values and standards attaching to their work. In this context, it is relevant to consider the difference between theories that are espoused, what people may believe that they do; and theories in use, what it is observed that they actually do in practice [1-3,7-9,10-13,19]. Williams [27] also supports this proposition with his discussion in the view of evidence gathered from approx 1600 IT projects. An example of this arises, for instance, actors in the field of Information Systems appear to ignore, or be confused by, the difference between applications of technology resulting from demand (pull), and applications developed because it is believed that demand will arise once they are available (push). They fail to perceive that there is a need for balance between these two forces. Related arguments are also made in discussions on socio-technical system development $[12-18,25,28]$. Technologically deterministic assumptions appear to prevail, at least in part. e.g. "if we only knew what stakeholders (users) find useful and easy to use they would actually use the technological solutions we develop". This aspect is visible in, for instance, in applications of TAM (the Technology Acceptance Model) [29,30]. This model is based on a theory of reasoned action and entails measurement of two factors - perceived usefulness of technology and perceived ease of use. TAM can be criticized because it is based upon simplifying assumptions of pure rationality. It ignores context of use and a crucial factor which is desire to engage with the technology concerned. Thus, although it is easy to imaging that someone might reject technology that she perceived to be both useless and difficult to use, TAM fails to address what is involved in determining 'usefulness' for particular individuals in their contextual roles [e.g.12-18,31,32]. McGrath [33] discusses emotion in the context of the much-researched failure in the London Ambulance Service Computer Aided Despatch System, from the early 1990's. In this project, the prevailing culture of public service and empathic support for patients within LAS came into direct conflict with a rational planning ethic intended to increase 'efficiency'. McGrath reflects that: "The case reveals that existing, even apparently latent, conflicts and emotions may surface or heighten when IS innovation is attempted. In the LASCAD case, these subjugated knowledges and emotions emerged during efforts to achieve cultural change of the LAS through the use of ICTs inscribed with governmentdriven efficiency logic" [p.297]. In the sections that follow, we discuss professional commitment to action as involving more than rational, role based activities but involving exercise of will to adhere to a value system. The impact of extra role be- 
haviour [34-36] in this context will be highlighted as a key factor in achieving beneficial organizational change.

Rogers [37], in his discussion on diffusion of technology, does distinguish between different types of threshold. One type, for example, would be the difference between ignorance and knowledge of how a technology might be applied as a solution for a particular problem. This could be viewed as a key aspect of professional competence. Another threshold could be the difference between thinking about engagement and engagement itself. This is similar to the distinction between theory espoused and theory in use [19]. The difference between feeling positive about the idea of engagement and actually engaging is significant and something that for example exponents of TAM often fail to take into account [30]. The problem of engagement, and lack of reflection over this as a problem, can be viewed as a kind of self-deception. This is often promoted through use of certain language. For example, describing individuals who may engage with technology as 'users' has been problematised by researchers in the IS discipline [13-18]. Failure to challenge prejudices such as this have also been recognized [19,26,31]. Specifically, the discourse about intention often fails to take into consideration the real investment of personal resources needed to address the required 'unlearning' [13-18], and an unwitting belief in rational behaviour as if professional life could be conducted without any emotion. This is ironic, as engagement is explicitly dependent on emotional status and process. As suggested above, an important factor in professional life is a desire to espouse a transcendent system of values that we describe by the term 'professional pride'. However, it is possible to draw a distinction between here between desire and the will to realise that desire in practice. Consider an alcoholic. He possibly has more than one 'desire'. On the one hand, he desires a drink. On the other, he desires to escape from the negative consequences of being addicted to alcohol. It is his will that determines which of these desires is acted upon, i.e. the will to go to the bar and satisfy one desire or the will to attend a meeting of Alcoholics Anonymous and address the other. Thus, we can see that the interaction between desire and exercise of 'free will' is not to be viewed as straightforward. We can detect a process of navigation between alternative desires, assessment of risks, weighing up of consequences; or refusing to consciously weigh up consequences $[2,3,14,22,23,26]$. Sometimes, a person may find himself entrapped in a double bind situation where he feels that there are no choices open to him that will meet his desires $[2,3,14,16,26]$. This might be due to a lack of recognition of choices that are available, or perhaps his ability to create choices is inhibited by factors he has not learned to navigate. Louis Brandeis, US Supreme Court Justice, is often quoted in relation to his dissenting judgment in Olmstead v United States 1928, which related to Government tapping of telephone wires [38]. He suggested that 'The greatest dangers to liberty lurk in insidious encroachment by men of zeal, well-meaning but without understanding.'

Engagement (desire and will to act) is not sufficient in itself. Competence in judgment is also required. However, this will not necessarily lead to engagement on its own. Dogmatic, closed-minded thinking (e.g. 'my country, right or wrong) leads to action without (personal awareness or recognition of) judgment. In the 
examples above, the impact of desire, will and their roles in creating choices for action may appear obvious. It is not always so obvious in organizational life $[7,8,14,16]$. However, the interactions between competence, desires and exercise of will are quite similar. This is highlighted by Maister in writing about business strategy [39], who suggests: "Discussing 'strengths, weaknesses, opportunities and threats' ... is fun, but gets nowhere near the real questions. Improving the quality of the analysis is not where the problem lies. The necessary outcome of strategic planning is not analytical insight but resolve. ... Discussing goals is stimulating, inspiring, and energizing. But it feels tough, awkward, annoying, frightening, and completely unpleasant to discuss the discipline needed to reach those goals" [p.6]. In the light of these comments, it becomes easier to recognize the importance of commitment to a set of values (professional 'pride') that guides our judgment and exercise of will in a work context. The next section of this paper examines the interaction between competence and exercise of judgment in context.

\section{Engagement and Competence}

Possession of relevant skills and knowledge for a work role is not sufficient to support professional practice without ability to exercise judgment in exercising those skills, related to a system of values that transcend the immediate context. This is fundamentally concerned with professional engagement. An illustration of the interplay between engagement (desire/will) and competence can be found in the field of music. Competence relates to ability to play a particular piece of music on an instrument. Engagement would relate to a wish to play in certain circumstances. The two aspects are related but possibly only loosely. For instance, people may gather around the piano in a bar for a 'sing song'. Someone who knows how to play the piano seats himself to pick out the tune for them. He may not be the most competence pianist in the room, but the person with the best combination of competence to play and desire to join in the fun! Sometimes, people are technically competent to play but play without feeling, e.g. a child who has been compelled to learn by his parents who duly practices the exercise set by his teacher but has no desire to express himself through music and so plays 'mechanically'. Competence in technique and competence in expression arise through exercise of will, motivated by different aspects of desire.

In relation to Information System, as in music, desire relates to exercise of will only as we open up space to create choices for ourselves. In a professional context, reflection is needed to negotiate such creative spaces [16-18,39,40]. These can become blocked through inappropriate management assumptions [40-43]. There is a need for design practice to address the whole work system and not just systems for use of particular artefacts. It is necessary to reflect upon one's professional role, on one's engagement in that role, and on engagement of the 'others' in order to avoid becoming entrapped in a double bind [2,3,13,14,44]. Williams' [27] commentary on failure in IT projects is interesting here. He observes that a cognitive discourse is often used to explain behaviour which is actually only explicable 
through the affective domain. Williams is able to see this because he is emotionally detached himself from the situations upon which he is reflecting. However, surprisingly enough, in his conclusion he then falls into the same 'modus operandi' as those he criticizes; in his recommendations Williams turns to a rational proposition for "more of the same". Engaged actors are caught in a double bind in which they cannot create those choices that would empower escape. It is possible to observe 'disconnectedness', i.e. failure to reflect. Engagement within a professional context is related to the phenomenon of extra role behaviour. It is possible that roles themselves can only be sustained through exercise of extra role behaviour. We are faced with complexity of multiple, competing desires in many contexts $[2,3,19,45]$. This is partly due to the impact of opportunity cost - any choice to expend finite resources, including time, involves choosing between priorities. Boundary setting $[2,3,28,42]$ is also involved, however. Channeled desire (i.e. exercise of will) comes about through commitment to certain values and consequences. Efforts to recognise boundaries of competence involve extra role behaviour (e.g. consider the difference between playing the piano and 'playing with the piano' as a jazz musician does when he extemporises from the original melody). The potential to go beyond the basic requirements of a role in order to create new boundaries involves a higher level of reflection. See Ciborra's comment [10,p2] on the MIR space station in relation to bricolage. "A good example is the adventurous (and long) life of the Russian MIR space station Up there, revolving in space, one could find, hand in hand, advanced, robust engineering solutions, rustic deign, and widespread virtuoso tinkering ... to keep the equipment and the system going as a whole. MIR has been a staccato technology, able to defy the passing of time, the inevitable downgrading of performance, and major and minor breakdowns, providing another opportunity for all to see the approximations of science and technology in use."

Such 'extra role behaviour' becomes possible only through commitment to ongoing reflection upon competence. The distinction between theories espoused and theories in use [19] is relevant here. How do we reflect upon our extra role behaviour? There is also paradox in that a professional engaged in such extra role behaviour must reflect upon 'the future' whilst still involved in creating it. Such reflection involves higher orders of learning $[2,3,16]$ in which the individual concerned is reflecting not only upon experience, but upon the process of reflecting on exercising judgment. This may be regarded as an exercise in practical philosophy as part of professional competence in action.

In this paper, we have looked at the nature of professional commitment and how transcendence value systems, professional 'pride' and the exercise of judgment are important in creation of beneficial organizational developments. We suggest that individuals acting within their role contexts should be viewed through such a lens, rather than as receiving 'users' of technology whose individuality and commitment disappear within a deterministic view of organizational life, in which rational models are privileged. Our conclusion is that it is of utmost importance that efforts made within IS must engage contextual dependencies from a critical perspective, in order to promote systems that are experienced as contextually relevant. What Klein and Meyers [46] describe as an explicit critique and improve- 
ment of social condition is necessary to develop richer meanings and understandings. Most importantly, it is necessary to entice people to speak out. In the absence of such an agenda, how are we to evaluate our efforts to support organizational change perceived to be beneficial by involved stakeholders? Only if those on whose behalf we speak are given appropriate opportunities to judge the results of their own and our activities can progress be made. A renewed emphasis on professional competence as including exercise of judgment, through engagement in extra role behaviour, is needed. The myth of the passive receiving 'user' needs to be abandoned in favour of recognition of organizational as communities of professionals, all of whose perspectives are relevant to the arena of decision-making and creation of beneficial change.

\section{References}

1. Lindblom C.E. (1959). The Science of Muddling Through. Public Administration Review. 19(2), 79-88.

2. Bateson G. (1972). Steps to an Ecology of Mind. University of Chicago Press.

3. Bateson G. (2002). Mind and Nature: a Necessary Unity. 5th edition. Hampton Press.

4. Mintzberg H. (1979). The Structuring of Organizations: a synthesis of the research. Englewood Cliffs: Prentice-Hall.

5. Mumford E., Hirschheim R., Fitzgerald G., Wood-Harper T. (Eds.) (1985). Research Methods in Information Systems. New York: North-Holland Publishers.

6. Nissen H-E., Klein H.K, Hirschheim R. (Eds.) (1991). Information Systems Research: Contemporary Approaches and Emergent Traditions. The Netherlands: Elsevier Science.

7. Weick K.E. (1995). Sensemaking in organizations. Thousand Oaks: Sage.

8. Weick K.E. (1998). Improvisation as a mindset for organisational analysis. Organisation Science, 9(5), 543-555.

9. Ciborra C. (2000). From control to drift. Oxford: Oxford University Press.

10. Ciborra C.U. (2002). The labyrinths of information. Oxford: Oxford University Press.

11. Ciborra C.U. (2004). 'Encountering information systems as a phenomenon,' in Avgerou C., Ciborra C.U., Land F. (editors), The Social Study of Information and Communication Technology. Oxford University Press

12. Whitaker R. (2007). Applying phenomenology and hermeneutics in IS design: A report on field experiences. in Nissen H-E., Bednar P.M. and Welch C. (Eds.) Use and design in IS: Double helix relationships? Santa Rosa, California: Informing Science Press.

13. Nissen H-E (2002). Challenging Traditions of Inquiry in Software Practice. In Dittrich Y., Floyd C., Klischewski R. (eds.). Social Thinking-Software Practice. 71-89. MIT Press.

14. Bednar P.M., Welch C. (2008). 'Bias, Misinformation and the Paradox of Neutrality.' Informing Science. (11) 85-106, 2008.

15. Bednar P.M., Welch C. (2009). 'Paradoxical Relationships in Collaboration, Competition and Innovation: a Critical Systemic Perspective,' WOA 2009, Proceedings.

16. Bednar P.M., Welch C. (2009). 'Inquiry into Informing Systems: critical systemic thinking in practice', Chapter 14 in G. Gill, editor, Foundations of Informing Science. Santa Rosa, California: Informing Science Press.

17. Bednar P.M. (2000). A Contextual Integration of Individual and Organizational Learning Perspectives as part of IS Analysis. Informing Science. 3(3), 145-156. 
18. Nissen H-E., Bednar P., Welch C. (2007). 'Double Helix Relationships in Use and Design of Informing Systems: Lessons to Learn from Phenomenology and Hermeneutics'. Informing Science. (10) 1-19.

19. Argyris C. (1990). Overcoming Organizational Defenses. New Jersey: Prentice Hall.

20. Mumford M.D., Scott G.M., Gaddis B., Strange J.M. (2002). Leading creative people: orchestrating expertise and relationships. Leadership Quarterly, (13), 705-750.

21. Etzioni A. (1968). The Active Society. New York: The Free Press.

22. Churchman C.W. (1968). The Systems Approach. Dell Publishing.

23. Churchman C.W. (1979). The Systems Approach and its Enemies. Basic Books.

24. Lawler E.J. (2001). An affect theory of social exchange. The American Journal of Sociology. 1007(2), 321-352

25. Baskerville R., Land F. (2004). Socially self-destructing systems. in Avgerou C., Ciborra C. Land F. (Eds.), The Social Study of Information and Communication technology. Oxford University Press.

26. Gilovich T. (1991). How we know what isn't so. New York: The Free Press.

27. Williams P. (2007). 'Make sure you get a positive return,' Computer Weekly, 13 Nov 2007

28. Langefors B. (1995). Essays on Infology. Lund: Studentlitteratur.

29. Davis F.D., Bagozzi R.P., Warshaw P.R. (1989). User acceptance of computer technology: A comparison of two theoretical models. Management Science, 35, 982-1003

30. Lee Y., Kozar K.A. and Larsen K.R.T. (2003). The Technology Acceptance Model: Past, Present, and Future. Communications of the AIS, 50(12), 752-780.

31. Bednar P.M. and Welch C. (2006). 'Incentive and desire: covering a missing category.' MCIS 2006. Proceedings, Università degli Studi di Trento, San Servolo, Venice. October

32. Bednar P., Welch C. (2007). 'A Double Helix Metaphor for Use and Usefulness in Informing Systems'. Informing Science. (10) 273-295.

33. McGrath K. (2006). 'Affection not affliction: The role of emotions in information systems and organizational change,' Information and Organization, (16), 277-303

34. Organ D.W. (1988). Organizational citizenship behaviour: The good soldier syndrome. Lexington Books.

35. Nemeth C.J., Staw B.M. (1989). The tradeoffs of social control and innovation in groups and organizations. in Berkowitz L. (Ed.) Advances in experimental social psychology, vol 22, 175-210. New York, Academic Press.

36. Van Dyne L., LePine A.J. (1998). Helping and voice extra-role behaviour: Evidence of construct and predictive validity. Academy of Management Journal. 41, 108-119.

37. Rogers E.M. (2003). Diffusion of Innovations. New York: The Free Press.

38. Brandeis, L. (1928). Dissenting judgment of Justice Brandeis in Olmstead v United States 277US479(1928), $129 \quad$ May $\quad 2009$

http://caselaw.lp.findlaw.com/scripts/getcase.pl?court=US\&vol=277\&invol=438

39. Maister D. (2008). Strategy and the Fat Smoker. Spangle Press

40. Bednar P.M., Welch C. (2006). 'Structuring uncertainty: sponsoring innovation and creativity', in Adam F., Brezillon P., Carlsson S., Humphreys P. (2006). Creativity and Innovation in Decision Making and Decision Support, (2) 867-886. London: Decision Support Press.

41. Friis S. (1991). User Controlled Information Systems Development. Lund University Publ.

42. Checkland P., Holwell S. (1998). Information, Systems and Information Systems. Chichester: Wiley.

43. Mumford E. (2003). Redesigning Human Systems. London: IRM Press.

44. Bednar P.M, Welch C., Depaoli P. (2007). 'Transformation of Information Systems: Relevance of Expectations'. MCIS 2007, Università degli Studi di Trento, Venice. October.

45. Bednar P.M., Welch C. (2007). 'Loitering with intent: dealing with human-intensive systems'. In D'Atri A., DeMarco M., Casalino N. (eds.) (2008). Interdisciplinary Aspects of Information Systems Studies. 33-41. Heidelberg: Physica Verlag.

46. Klein H.K., Meyers M.D. (2009). A set principles for conducting and evaluating critical field studies in information systems. Working paper. 
